\title{
DECISIONS
}

\section{A woman with a family history of glaucoma}

\author{
Alfred Basilious BSc, Yvonne M. Buys MD \\ See also page E398 and www.cmaj.ca/lookup/doi/10.1503/cmaj.140401
}

\begin{abstract}
A 65-year-old woman of African descent presents to a primary care clinic for routine follow-up. She has not noted any change in her vision. Her last eye examination was six years earlier. Her mother had been given a diagnosis of glaucoma in her 70s, and there is a family history of blindness. On examination, there is no change in the woman's visual acuity or field.
\end{abstract}

\section{Does this patient require screening for glaucoma?}

Even though the patient has no symptoms, she is at increased risk of glaucoma and requires screening. Primary open-angle glaucoma is typically asymptomatic until it is advanced. ${ }^{1}$ Patients usually do not report changes until their visual field or acuity is substantially impaired. As a result, glaucoma may be undiagnosed in $50 \%$ of patients with the disease. ${ }^{1}$ By the time visual symptoms present, the disease is quite advanced, and irreversible damage to the optic nerve has occurred. An evidence-based guideline from the Canadian Ophthalmological Society recommends glaucoma screening in patients at high risk of glaucoma. ${ }^{2}$

Several risk factors are easily elicited on history-taking. Increasing age is related to increased risk of glaucoma. The Blue Mountains Eye Study (involving an urban population from the Blue Mountains region, west of Sydney, Australia) showed a prevalence of glaucoma of $3 \%$ among people over 49 years of age and $8.17 \%$ among those over $80 .{ }^{1}$ African descent is an important risk factor: the prevalence of glaucoma is 4.3 times higher in this population than among white people. ${ }^{2}$ Patients with a firstdegree family history of glaucoma are at increased risk. ${ }^{2}$ Topical (ocular) or periocular corticosteroid use is frequently associated with increased eye pressure, which, if unrecognized, can lead to glaucomatous vision loss. ${ }^{3}$ Other risk factors for primary open-angle glaucoma include myopia and migraine. ${ }^{2}$
Patients who have not had an eye exam in more than five years are considered to be at risk of undiagnosed glaucoma. Only 27\%-64\% of Canadians attend regular eye exams. ${ }^{4}$ The Canadian Ophthalmological Society recommends a complete eye exam every five years for people 41 to 55 years old, every three years for those 56 to 65 , and annually for those over $65 .{ }^{5}$ In particular, patients using corticosteroids (topical [ocular], periocular or systemic) for more than two weeks should have an eye exam to establish a baseline status and undergo regular monitoring to rule out pathological changes (e.g., elevated eye pressure, cataracts). ${ }^{3}$

\section{What should be assessed on physical examination?}

Assessment of visual field (confrontational testing) and visual acuity (Snellen chart) in the primary care clinic may detect symptomatic advanced glaucoma that requires referral. The swinging light test is used to identify a relative afferent pupillary defect, in which both pupils dilate when the light is directed at the affected eye (Figure 1). This defect may indicate advanced glaucoma, among other serious ocular pathology, and requires prompt referral. ${ }^{2}$

If accurately performed by the primary care physician, direct ophthalmoscopy is a useful tool to investigate asymptomatic glaucomatous optic neuropathy. Assuming a normal size optic nerve, a cup-to-disc ratio greater than 0.5 suggests possible glaucoma and warrants referral. ${ }^{2}$ Other findings that require referral include a difference of more than 0.2 between the cup-to-disc ratios of both eyes, an inferior disc notch, a nerve fibre layer defect or disc hemorrhage (examples are shown in Appendix 1, at www.cmaj.ca/lookup/suppl /doi:10.1503/cmaj.140685/-/DC1). If available, a tonometer should be used to measure intraocular pressure in patients at high risk. Elevated intraocular pressure $(>22 \mathrm{~mm} \mathrm{Hg}$ ) is an important risk factor for glaucoma. However, because 50\% of patients with glaucoma have normal pressure, this finding does not rule out the disease. ${ }^{2}$
Competing interests:

Yvonne Buys received a grant from the Canadian Ophthalmological Society for the development of the guide in Appendix 1, and speaker fees from Alcon

Canada, Allergan Inc., and Pfizer Canada; she is a member of the board of the Canadian Ophthalmological Society. No competing interests were declared by Alfred Basilious.

This article has been peer reviewed.

Correspondence to:

Yvonne Buys,

y.buys@utoronto.ca

CMAJ 2015. DOI:10.1503

/cmaj.140685 


\section{Normal swinging light test}

1. Begin with dark room, bright pen light and patient fixated at distant object (to avoid a near pupil response).

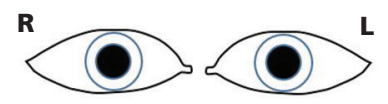

2. Shine light into right (R) eye. Both pupils should constrict.

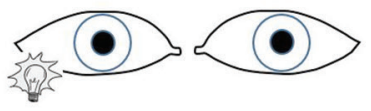

3. Swing light to left (L) eye. Both pupils remain constricted.

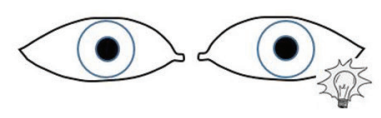

4. Swing light back to right eye. Both pupils remain constricted.

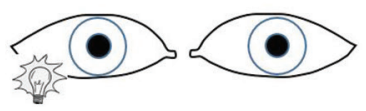

\section{Left relative afferent pupillary defect* (RAPD)}

1. Begin with dark room, bright pen light and patient fixated at distant object.

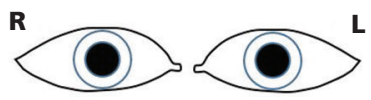

2. Shine light into right (R) eye. Both pupils should constrict.

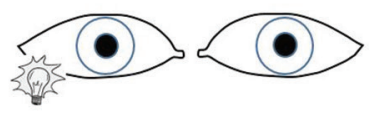

3. Swing light to left (L) affected eye. Instead of pupil constriction, both pupils will dilate.

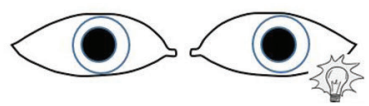

4. Swing light back to right (normal) eye. Both pupils constrict.

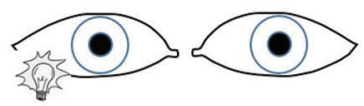

A RAPD indicates unilateral or asymmetric optic nerve pathology (e.g., asymmetric glaucoma) or retinal disease and should always be referred to an optometrist or an ophthalmologist.

*In a right RAPD, both pupils dilate when light is shone in the right eye during the swinging light test.

Figure 1: Instructions on how to perform the swinging light test to detect a relative afferent pupillary defect.

Does this patient require referral to an eye care specialist?

Patients at high risk of glaucoma, such as the patient described in this case, should be referred to an eye care specialist. ${ }^{2}$ Damage to the optic nerve and loss of visual field in glaucoma is progressive, chronic and irreversible. Late diagnosis is associated with a higher rate of blindness. Lowering intraocular pressure with drops, laser or surgery can halt or delay disease progression, as shown in the Early Manifest Glaucoma Trial (a well-powered randomized controlled trial). ${ }^{6}$

\section{Case revisited}

The patient's visual field and visual acuity were normal. A vertical cup-to-disc ratio of 0.8 was found in the right eye with direct ophthalmoscopy. The patient was referred to an eye care specialist for assessment, and moderate primary open-angle glaucoma was diagnosed. Medication in the form of eye drops was prescribed to lower the intraocular pressure, and the patient was monitored for potential ocular and systemic adverse effects. ${ }^{2}$ She is followed regularly by her ophthalmologist for assessment of intraocular pressure, optic disc changes and visual field. A decade after her presentation, she continues to enjoy good visual function owing to early detection and treatment of the glaucoma.

A brief guide for primary care physicians to aid in the screening and referral of patients at risk of glaucoma is available in English and French (see Appendix 1, at www.cmaj.ca/lookup/suppl/doi:10.1503/cmaj.140685 /-/DC1). The guide has been endorsed by the Canadian Ophthalmological Society, the Canadian Association of Optometrists, the Canadian Glaucoma Society and the College of Family Physicians of Canada.

\section{References}

1. Mitchell P, Smith W, Attebo K, et al. Prevalence of open-angle glaucoma in Australia. The Blue Mountains Eye Study. Ophthalmology 1996;103:1661-9.

2. Canadian Ophthalmological Society Glaucoma Clinical Practice Guideline Expert Committee, Canadian Ophthalmological Society. Canadian Ophthalmological Society evidence-based clinical practice guidelines for the management of glaucoma in the adult eye. Can J Ophthalmol 2009;44(Suppl 1):S7-93.

3. Kersey JP, Broadway DC. Corticosteroid-induced glaucoma: a review of the literature. Eye (Lond) 2006;20:407-16.

4. Jin YP, Trope GE. Eye care utilization in Canada: disparity in the publicly funded health care system. Can J Ophthalmol 2011; 46:133-8.

5. Clinical Practice Guideline Expert Committee. Canadian Ophthalmological Society evidence-based clinical practice guidelines for the periodic eye examination in adults in Canada. Can J Ophthalmol 2007;42:39-45, 158-63.

6. Heijl A, Leske MC, Bengtsson B, et al. Reduction of intraocular pressure and glaucoma progression: results from the Early Manifest Glaucoma Trial. Arch Ophthalmol 2002;120:1268-79.

Affiliations: Faculty of Medicine (Basilious) and Department of Ophthalmology and Vision Sciences (Buys), University of Toronto, Toronto, Ont.

Contributors: Alfred Basilious drafted the article. Yvonne Buys critically revised the article. Both authors were involved in the article conception and design, gave final approval of the manuscript submitted for publication and agreed to act as guarantors of the work.

Acknowledgments: Francine Borduas, Mark Kazimirski, Paul Rafuse, Jim McGorman and Pierre Blondeau contributed to the development of the guide in Appendix 1. 